\title{
Proposal of a Social Responsibility Indicator Model Based on Systems Dynamics
}

\author{
Liliana Ruiz Acosta ${ }^{1}$, David Andrés Camargo Mayorga ${ }^{2}$, Mauricio Becerra Fernández ${ }^{3}$ \\ ${ }^{1}$ Full-time professor, Universidad Militar Nueva Granada, Bogotá, Colombia, liliana.ruiz@unimilitar.edu.co \\ ${ }^{2}$ Full-time professor, Universidad Militar Nueva Granada, Bogotá, Colombia, david.camargo@unimilitar.edu.co \\ ${ }^{3}$ Research Assistant, Universidad Militar Nueva Granada, Bogotá, Colombia, mauriciobecerrafernandez@gmail.com
}

\begin{abstract}
This document presents the advances in the construction of an indicator model based on the economic, social and environmental dimensions, which serve to measure the performance of manufacturing companies in terms of Social Responsibility (SR). To model the proposed indicator, the methodology of system dynamics using the iThink ${ }^{\circledR}$ software is used. The main reference for this construction is the work carried out by Pavláková Dočekalová and Kocmanová (2016) that proposes the Complex Performance Indicator (CPI). The sectors that make up the model are two: physical flow, which includes production, workers, innovation, marketing and machines; and information flow, which is represented in Key Performance Indicators (KPI) and in the CPI sector that calculates the consolidated indicator of the three groups (environmental, social and economic). The work contributes to the measurement of the performance of companies that engage in SR actions and shows the relationships and causalities between the sectors and indicators mentioned above.
\end{abstract}

KEYWORDS: systems dynamics, social responsibility, dynamic indicators, sectors, sustainability

\section{Introduction}

The evolution of Social Responsibility (SR) has taken place from academic and institutional perspectives. The latter has elicited international regulations that have set off from guiding principles such as those promoted by the United Nations (UN), and have escalated up to industryspecific codes. In this sense, Rodríguez (2018) has called as "hard law" the regulations on SR originating in organizations such as the UN, the European Union (EU) and the World Trade Organization (WTO), and "soft law" the guidelines on SR by the Organization for Economic Cooperation and Development (OECD) and other private bodies, which propose codes of conduct that have been adapted by national and transnational companies.

The influence of "hard law" has promoted worldwide the adherence of companies to initiatives such as the Global Compact (GC), as a mechanism to develop an SR management system and the use of the Global Reporting Initiative (GRI) as a methodology for the preparation of sustainability reports. In this sense, organizations use these reports to legitimize their activities and the use of sustainability indicators (Bradley and Botchway, 2018).

The GRI collects the three lines established by Elkington (1998) in the concept of sustainability, establishing a series of indicators that allow measuring the economic, social and environmental performance that a company can have. For adequate performance, these three dimensions must be balanced; however, it is common for them to move independently, generating friction between them or leading to situations where they are located above, below or next to each other (García, 2015), generating an imbalanced performance.

In the reports presented by companies through the GRI, they are observed to engage in different practices, and although they are reported qualitatively or quantitatively, they do not allow to determine their contribution to the performance of a specific dimension.

In this sense, the present work, using system dynamics as a methodology for modeling, shows the advances in the construction of a consolidated indicator on the performance of companies in terms of SR, fed by indicators for the economic, social and environmental dimensions. This proposal starts by recognizing that there is no single way to measure socially responsible activities (Wolfe and Aupperle 1991) and that the relationship between dimensions is still in the exploratory phase. 
The main reference for this construction was the work carried out by Pavláková Dočekalová and Kocmanová (2016) from which the Complex Performance Indicator (CPI) was obtained. This research is justified by the fact that companies should use computerized systems to manage SR, ensuring the adoption of best practices that lead them to obtain competitive advantages (Campos and Grangel, 2018) and thus improve their performance. Thus, a contribution is made in the area of socio-environmental modeling, because a dynamic indicator allows the continuous evaluation of variables to project and control practices, and implement improvements that contribute to social performance. For authors such as Crane, Hernriques, Husted, and Matten (2017) this issue still has questions that need to be resolved, and for which research still does not reflect enlightening results on SR measurements. This document is organized as follows: introduction, literature review, methodology, results and conclusions.

\section{Literature Review}

SR is a multidimensional concept that is often measured using various indicators. One of the mechanisms that exist is synthetic or composite indexes, which aggregate different individual indicators into one measure, summarizing multidimensional concepts (Paredes-Gazquez, Rodríguez-Fernández and de la Cuesta-González 2016). However, composite indicators do not allow measuring changes that can occur in variables over a period of time, in that sense a Dynamics System (DS) provides a framework that allows managing changes through the understanding of dynamic interactions, delays and feedbacks integrated in complex systems (Rasmussen, Rasmussen, Reenberg and Proud 2012; Martínez-Fernández, Esteve-Selma, Baños-González, Carreño and Moreno, 2013; Zhao and Zhong 2015), as is the case of SR performance through economic, social and environmental dimensions.

For Baños-González, Martínez-Fernández and Esteve-Selma (2016), DS allow early decisions to be made in the long term, taking into account the consequences of these and of the actions undertaken, as well as the unintended consequences along with the uncertainty of policies and strategies. To fulfill this purpose, scenario development is one of the main tools used to visualize and compare the potential of the results of a variety of policies and strategies.

A DS corresponds to an approach that combines quantitative and qualitative analysis in order to understand the transformations that occur in a complex system (Zhao and Zhong 2015), which is applicable to an SR management system that involves the measurement of performance through indicators that are represented by means of methodologies such as the GRI. The limitation is that because it is composed of indicators whose application is widespread, it is difficult to measure the performance of SR. Thus, the difference in the outcome after processing is the effect of the process or the impact on what is being sought to measure (Crane, Hernriques, Husted, \& Matten 2017), therefore, to measure performance in the social, economic and environmental dimensions, it is necessary to organize the variables into a function that shows the changes in time and allow the necessary recalculations to be made.

To this end, an index must be built that takes into account the activities carried out by companies, which contribute to better social performance, and which in turn generate a balance between the three dimensions. Determining the weights to assign indicators is one of the main obstacles when constructing this type of index (Paredes-Gazquez, Rodríguez-Fernández and de la Cuesta-González 2016), wherefore building a truly representative measure is a challenge for the multidimensionality of theoretical constructions (Ioannou and Serafeim 2012) and external indicators related to social performance.

Within the development of indexes is the work developed by Shokravi, Smit, and Burvill (2014), who conducted an assessment on the environmental performance of industry based on the Markov model, to determine that operational and environmental performance are related. For the model, operational aspects were included regarding variables such as the rise and fall times, the environmental management system and the objectives of safety and machinery failure history, as well as inputs (raw materials such as water and energy) and outputs (products, waste and byproducts) used in the production process. 
Finally, Pavláková Dočekalová \& Kocmanová, (2016) they proposed a composite GRI standardsbased sustainability indicator, for which they identified variables in the environmental, economic, social and corporate governance, which resulted in indicators of these dimensions through linear functions.

\section{Methodology}

For the construction of the SR indicator, systems dynamics were used, a methodology used for various analyses, including simulation of logistical problems, and other analogous ones, as well as applications in supply chains and manufacturing systems (Aracil 1995).

Considering the methodological proposal of Becerra, González, Herrera and Romero (2016), progress was made for the purposes of this document in two of the four phases required for the construction of the system dynamics model based on the CPI designed by Pavláková Dočekalová and Kocmanová (2016), that is, we worked on the formulation of the problem and in the design of the model, phases that allowed identifying and quantifying the variables of the model from relevant data extracted from GRI reports of manufacturing companies adhering to PG Colombia, and using causal diagrams to identify the relationship between the variables involved. The dynamic indicator was worked in the iThink ${ }^{\circledR}$ software.

\section{Results}

The two main sectors, which were found to make up the model are shown in Figure 1 and are classified into:

- Physical flow sectors: in this group are the basic sectors for calculating indicators, such as production, workers, machines, marketing and innovation.

- Information flow sectors: These are the sectors derived from the physical flow, by which model result indicators are calculated. These are the sector of social KPIs, environmental KPIs, economic KPIs and the CPI.

Physical flow sectors are described as follows:

- Production sector: here the manufacturing process takes place, considering raw materials and materials, which are inputs. ${ }^{1}$ From the production process, stocks of the finished product are generated, which respond to the needs of demand in the market.

- Workers sector: the number of workers in the model responds to the production needs, taking into account times for the hiring and dismissal of these. Elements of occupational diseases, collective agreements, breaches of the code of ethics and wages are included.

- Innovation sector: this represents the company's innovation strategy. Increased innovation incentives result in improvements in the impact of products that affect safety and health.

- Marketing sector: This sector represents the marketing strategy of the company. Increased investment in marketing represents an increase in demand for the finished product.

- Machinery sector: shows the dynamics for acquisition and obsolescence of machinery, derived from the need for this resource by the manufacturing process.

Information flow sectors are described as follows:

- Environmental KPIs: include indicators of material consumption, energy consumption, waste production and environmental cost.

- Social KPIs: they include indicators of collective agreement workers, occupational diseases, products that impact safety and health, identification of customer needs, salaries and failures to the code of ethics.

- Economic KPIs: include cash flow and return on investment indicators.

- CPI sector: this calculates the consolidated indicator of the three previous groups (environmental, social and economic).

\footnotetext{
${ }^{1}$ The materials for manufacturing are the ancillary ones within the process, such as packaging.
} 


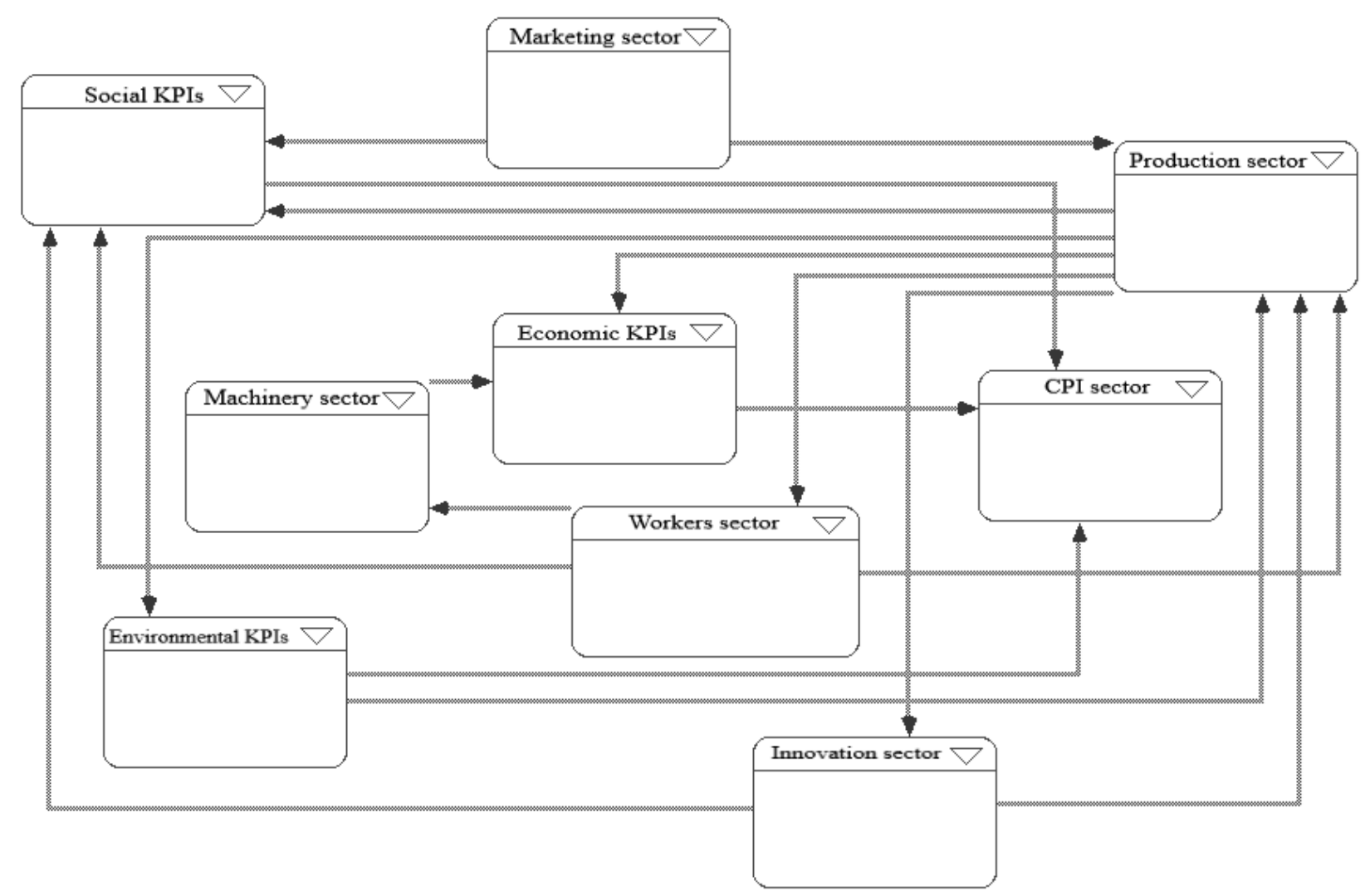

Figure 1. Diagram of relationships and causalities of the model for the dynamic indicator of social responsibility based on reports (GRI).

Source: Authors' Own elaboration

\section{Conclusions}

Measurement of the performance of manufacturing companies engaged in SR actions can be done through the CPI, which as a consolidated indicator of environmental, social and economic performance, includes KPIs.

KPIs are determined by the physical flow sectors, highlighting the bidirectional relationship between environmental KPIs and the production sector, by the waste flows that leave the manufacturing process and the recycling of these to be used back as inputs of the system.

The phases of the model that follow the construction presented here are two: the operationalization phase, where the verification and validation of the model will be carried out; and the measures and results phase, where the study of the "strategies" will be carried out through scenario analysis.

\section{Funding}

Product derived from the research project INV-ECO 2969 financed by the Vice Presidency for Research of the Universidad Militar Nueva Granada - 2019 term.

\section{References}

Aracil, Javier. 1995. System Dynamics. Madrid: Isdefe.

Baños-González, Isabel, Martínez-Fernández, Julia, and Esteve-Selma, Miguel. 2016. "Using dynamic sustainability indicators to assess environmental policy measures in Biosphere Reserves." Ecological Indicators 67: 565576. doi: 10.1016/j.ecolind.2016.03.021.

Becerra, Mauricio, González, Elsa, Herrera, Milton and Romero, Olga. 2016. "Collaborative planning capacities in distribution centers." In Theory, Methodology, Tools and Applications for Modeling and Simulation of Complex Systems, edited by Lin Zhang, Xiao Song, and Yunjie Wu, 622-632. Singapore: Springer. 
Bradley, Oliver, and Botchway, Gloria. 2018. "Communicating corporate social responsability (CSR) in the coffe industry: An examination of indicators disclosed". Sustainability Accounting, Management and Policy Journal 9(2): 139-164. doi: 10.1108/SAMPJ-02-2017-0015

Campos, Cristina, and Grangel, Reyes. 2018. "A domain-specific modelling language for Corporate Social Responsibility (CSR)." Computers in Industry 97:97-110. doi: 10.1016/j.compind.2018.01.007.

Crane, Andrew, Hernriques, Irene, Husted, Bryan, and Matten, Dirk. 2017. "Measuring corporate social responsibility and impact: enchancing quantitative research design and methods in bussiness and society research." Business \& Society 56(6): 787-795. doi: 10.1177/0007650317713267.

Elkington, John. 1998. Cannibals with forks: The triple bottom line of 21st century business. British Columbia: New Society Publishers.

García, María. 2015. "La cuenta del triple resultado o triple bottom line.” Revista de Contabilidad y Dirección 20:6577.

Ioannou, Ioannis, and Serafeim, George. 2012. "What drivers corporate social performance? The role of nation leve institutions." Journal of International Business Studies 43(9): 834-864.

Martínez-Fernández, Julia, Esteve-Selma, Miguel, Baños-Gonzalez, Isabel, Carreño, Francisca, \& Moreno, Angeles. 2013. Sustainability of Mediterranean irrigated agro-landscapes. Ecological Modelling 248: 11-19. doi: 10.1016/j.ecolmodel.2012.09.018.

Paredes-Gazquez, Juan, Rodríguez-Fernández, José, \& de la Cuesta-González, Marta. 2016. "Measuring corporate social responsibility using composite indices: Mission impossible? The case of the electricity utility industry." Revista de Contabilidad 19(1): 142-153. doi: 10.1016/j.rcsar.2015.10.001.

Pavláková Dočekalová, Marie, and Kocmanová, Alena. 2016. "Composite indicator for measuring corporate sustainability." Ecological Indicators 61:612-623. doi:10.1016/j.ecolind.2015.10.012.

Rasmussen, Laura, Rasmussen, Kjeld, Reenberg, Anette, and Proud, Simon. 2012. "A system dynamics approach to land use changes in agro-pastoral systems on the desert margins of Sahel." Agricultural Systems 107: 56-64. doi: 10.1016/j.agsy.2011.12.002.

Rodríguez, César. 2018. "Empresas y derechos humanos. Un marco conceptual y un mapa de estrategias regulatorias". In Empresas y derechos humanos en el siglo XXI, edited by César Rodríguez, 29-74. Buenos Aires: Siglo Veintiuno Editores.

Shokravi, Samaneh, Smit, Alan, and Burvill, Colin. 2014. "Industrial enviromental performance evaluatrión: A Markov-based model considering data uncertainty." Environmental Modelling \& Software 60:1-17. doi: 10.1016/j.envsoft.2014.05.024.

Wolfe, Richard, and Aupperle, Kenneth. 1991. "Introduction to Corporate Social Performance: methods for evaluating an elusive construct". In Research in Corporate Social Performance and Policy: an annual compilation of research, V12, edited by James Post, 265-268. Greenwich: JAI Press.

Zhao, Rui, and Zhong, Shaozhuo. 2015. "Carbon labelling influences on consumers' behaviour: A system dynamics approach.” Ecological Indicators 51: 98-106. doi: 10.1016/j.ecolind.2014.08.030. 